\title{
التعليم أولا أم الفقر أولا
}

\section{عبير صالح}

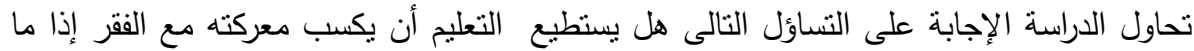

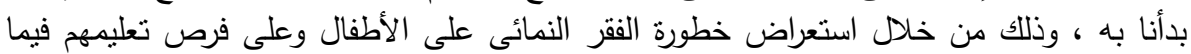

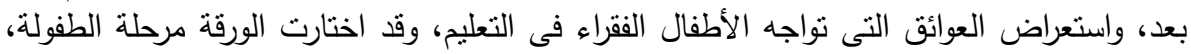

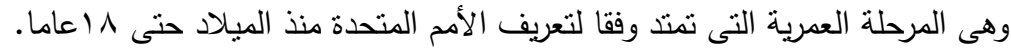

الاقدمهية

"التعليم أولاًا" هى مبادرة لخمس سنوات أطلقها الأمين العام للأمم المتحدة بان كى

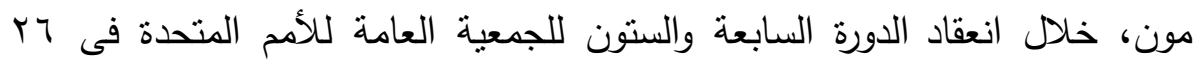
سبتمبر r I ـ r. وتهدف هذه المبادرة للترويج على أعلى المستويات لتحقيق الأهداف

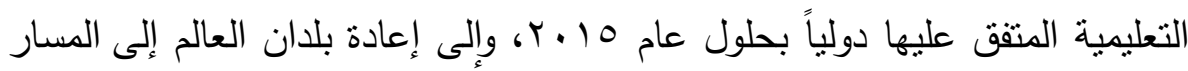
الصحيح لتفى بالالتزامات التى تعهدت بها فى مجال التعليم، وكذللك منح جميع الأطفال فرصة الحصول على مستوى ملائم من التعليم السليم الذى يحقق التغيير.

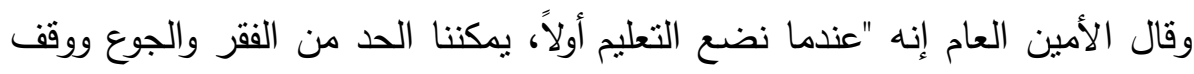
هدر القدرات والإمكانات كى ينعم الجميع بمجتمعات أقوى وأفضل". وتثمحور مبادرة "التعليم أولاً" حول الأولويات الثلاث التالية (') : • ض ضمان التحاق جميع الأطفال بالمدارس. 


$$
\text { • • تحزين جودة التعليم. }
$$

ومع الإقرار بأن التعليم بيساهم بشكل أساسى فى الحراك الاجتماعى وكسر

دائرة الفقر، وذللك لما يتيحه من فرص تغيير وضعية الفرد المهنية وتحركه اجتماعيا

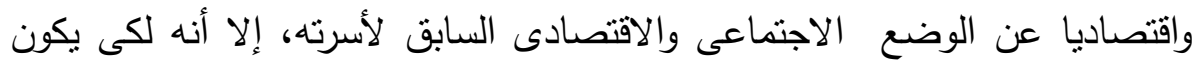

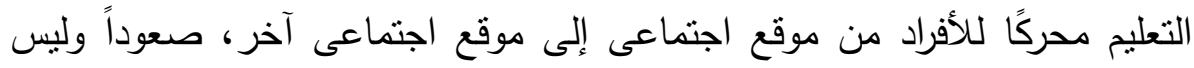

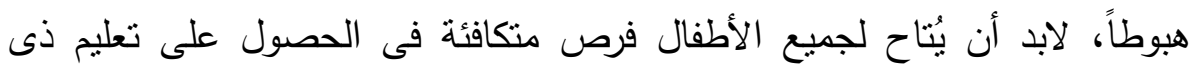

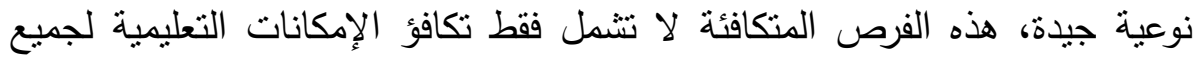
الأطفال، بل تثمل أيضا تكافؤ فرص النمو الجسدى والتطور العقلى. فملايين الأطفال الفقراء يلتحقون بالمدارس بعد أن تكون قدراتهم على التعلم قد تعرضت التعال

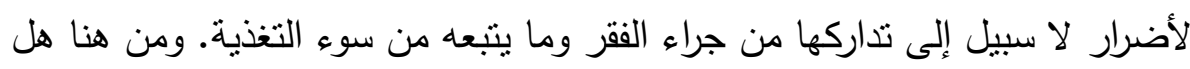

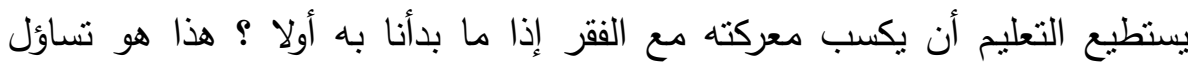

\section{التعليم أولا” أم الفقر أولاب؟}

وسوف تحاول الدراسة الإجابة عليه من خلال استعراض خطورة الفقر النمائى على الأطفال وعلى فرص تعليمهم فيما بعد، واستعراض العوائق التى تواجه الأطفال الفقراء

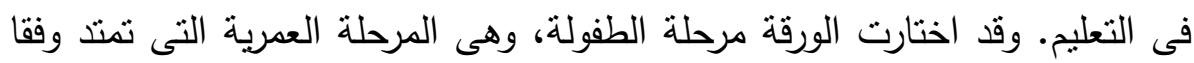

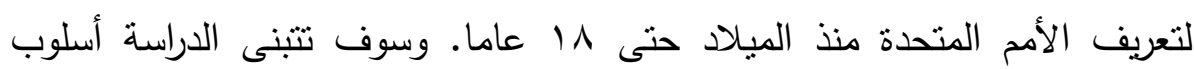
الوصف التحليلى فى منهجية الدراسة معتمدة على مصادر البيانات النالية:

\section{مصادر البيانات}

فى هذه الدراسة، نم استخدام النتائج النهائية لمسح الدخل والإنفاق والاستهلاك

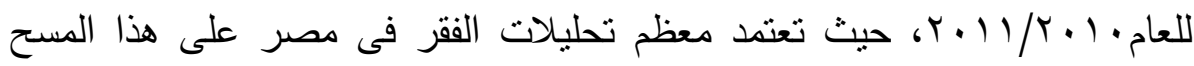
الذى يجريه الجهاز المركزى للتعبئة العامة والإحصاء (جهة الإحصاء الرسمية). 
بالإضافة إلى هذه البيانات نم استخدام بيانات آخر إصدار للمسح السكانى الصحى لمصر ^ . . r لقياس بعض المؤشرات التى لا يوفرها مسح الدخل والإنفاق والاستهلاك.

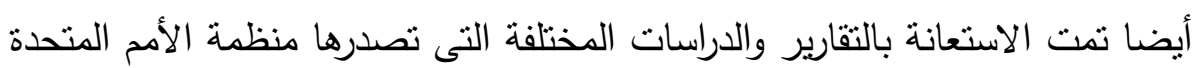

\section{أولا: خطورة الفقر النهائى على الأطفال وعلى فرص تعليسهم}

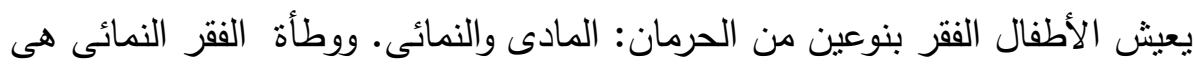

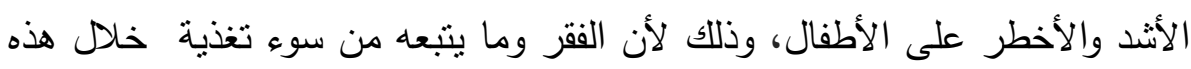
المرحلة له تأثثرات ضارة على النمو الجسدى وعلى النطور العقلى، تبقى آثاره دائمة

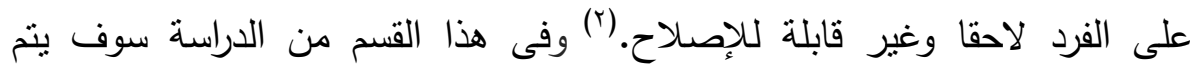
عرض الأسباب التى تجعل من آثار الفقر آثاراً دائمة على الأطفال، ثم سوف يتم

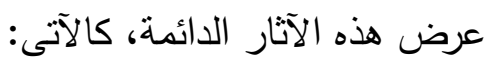

\section{الأسباب وراء الآثار الدائهة للفقر النهائى على الأطفال}

يُسبب الفقر فى مرحلة الطفولة وسوء التغذية ضررا مدى الحياة لعقول وأجسام الأطفال، ويمكن تفهم الأسباب النى تجعل من آثار الفقر آثاراً دائمة من خلال نتائج

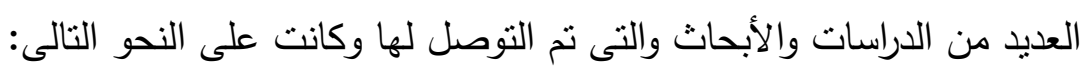

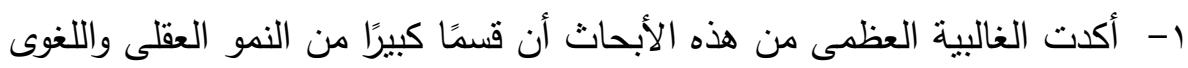

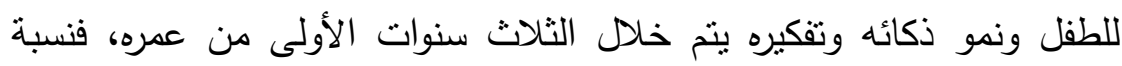

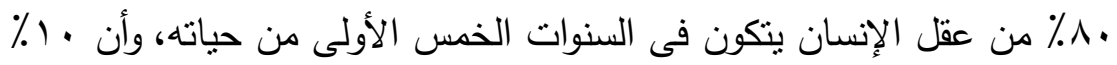

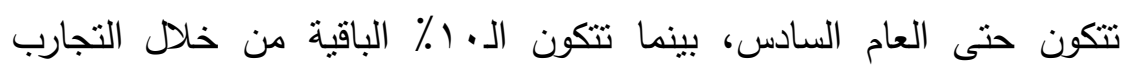

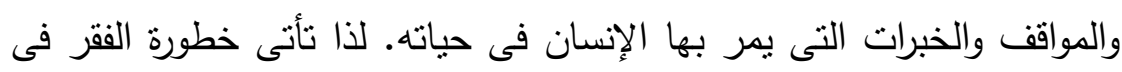

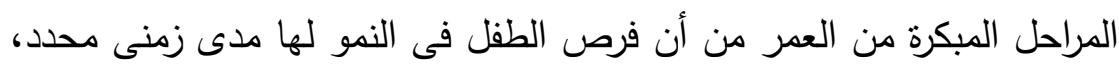

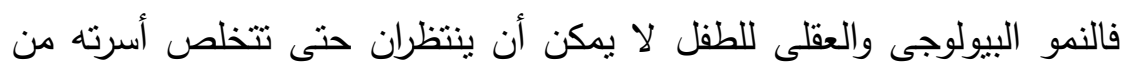


ץ- كما أثتت الأبحاث العلمية المختلفة أن الأثهر التشعة التي يمضيها الجنين

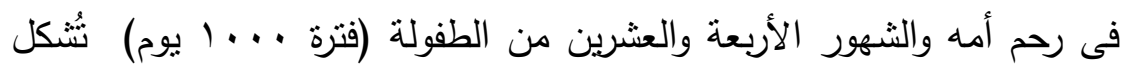
أهم الفترات الحساسة النى يمر بها الطفل. وتتسبب الآثار المدمرة النى يخلفها

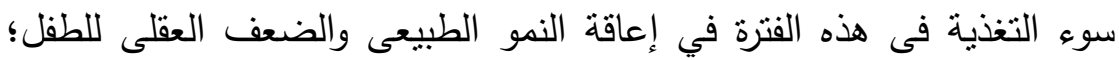

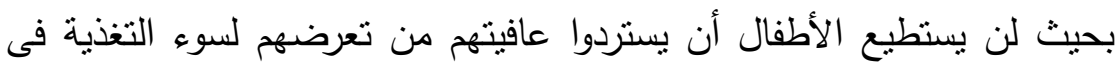
تلكك السن، ولن ينموا ويتطوروا إلى كامل إمكانياتهم الجسدية والعقلية، فالفقر في التى

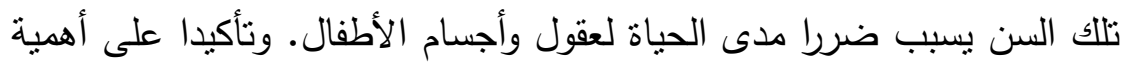
أول ألف يوم فى حياة الطفل عُقد منتىى بعنوان ".... يوم: غيّر حياة غيّر

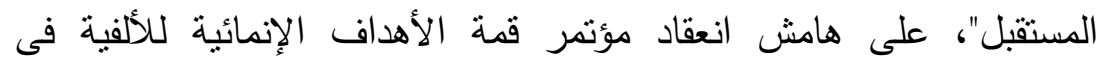

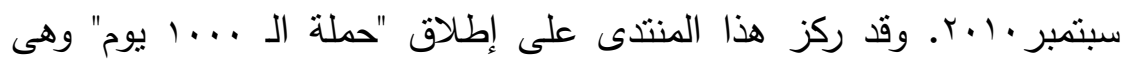

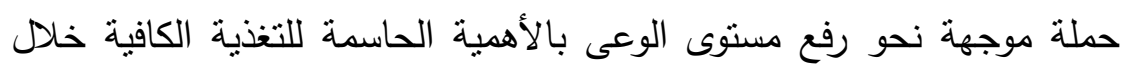

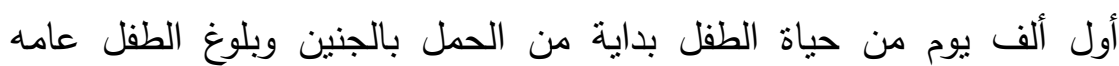
الثانى (₹)

r- أوضحت نتائج العديد من الدراسات والتى نم التوصل لها فى علم وظائف الدخ، والجهاز العصبى، أن معمار الدخ ينكون من عنصرين أساسيين: خلايا عصبية ووصلات بين هذه الخلايا تمكنها من الاتصال ببعضها، وتتحدد كفاءة

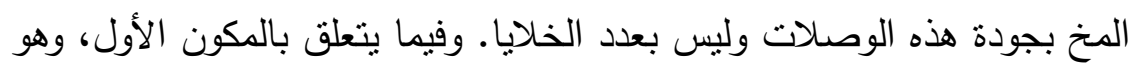

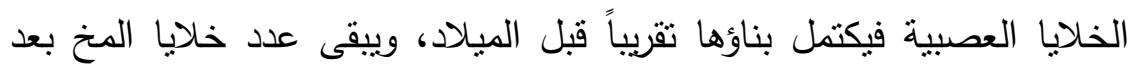

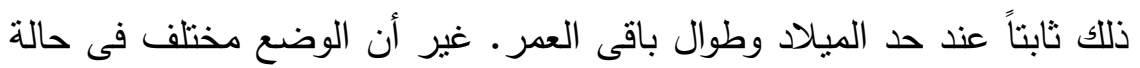

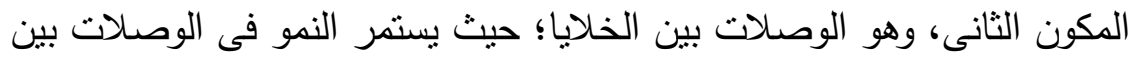

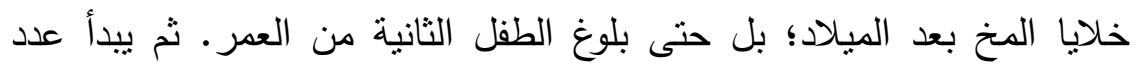
الوصلات فى التناقص، وعند سن العاثرة يكون عدد الوصلات قد تقلص إلى بلى حوالى النصف. ويلعب الفقر وما يتبعه من سوء تغذية فى سنوات الطفولة الأولى القى

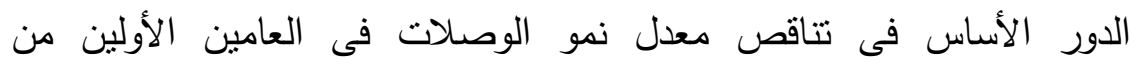


العمر (فى الفترة التى من الدفترض فيها أن تزيد)، وإلى الزيادة من معدل نقلص

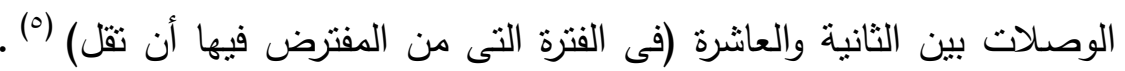
محدثة ضررا غبر قابل للتصويب حتى لو تم إددادهم بالغذاء المناسب لاحقا.

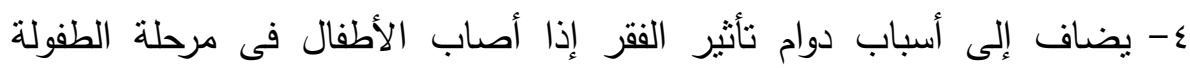

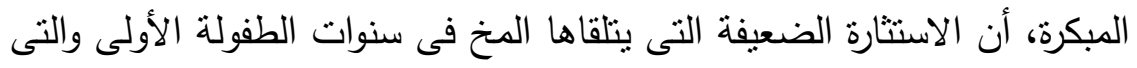

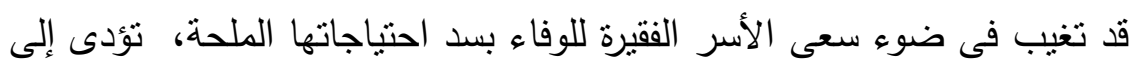

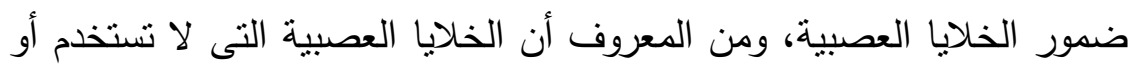

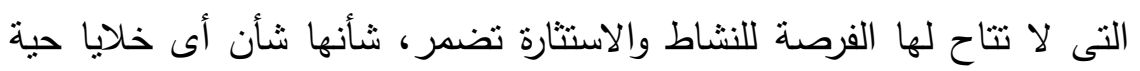
أخرى ينطبق عليها قانون الاستخدام وعدم الاستخدام، والخلايا العصبية التى لإنى تموت لا يمكن تجديدها(? آن.

\section{تأثير الفقر على فرص تعليم الأطفال فى المستقبل}

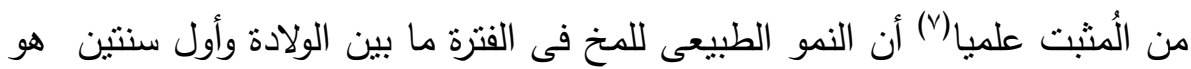

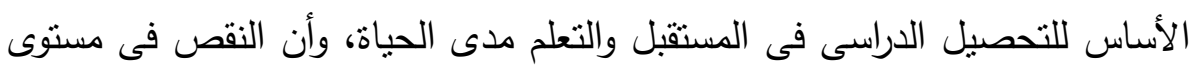

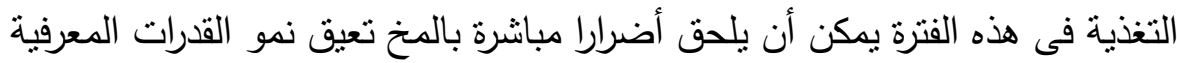
وتقف عائقا فى طريق التعليم. ويتم تقيبم الحالة التخذوية للأطفال باستخدام مؤشرات الحالة التغذوية، وتتاول العناصر الغذائية الدقيقة، وتتضمن مؤشرات الحالة التغذوية،

مؤشرات الحالة التغذوية الثلاثة، المؤشرات القياسية الثالية للنمو (^):

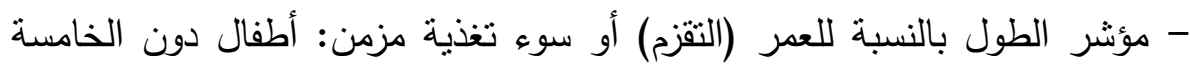

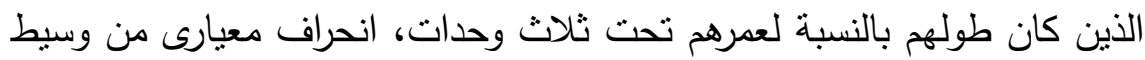
المجتمع المرجعى الدولى لنمو الطفل. - مؤشر الوزن بالنسبة للطول (الهزال) أو سوء التخذية لفترة قصيرة: أطفال دون

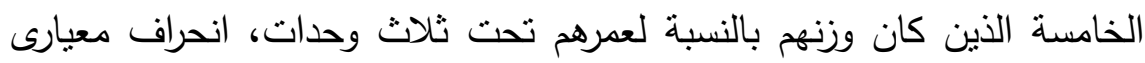
من وسيط المجتمع المرجعى الدولى لنمو الطفل.

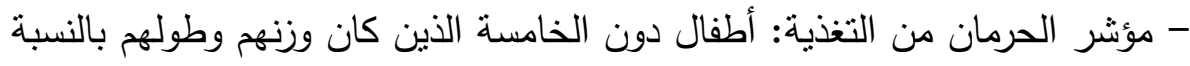


لعمرهم تحت ثلاث وحدات، انحراف معيارى من وسيط المجتمع المرجعى الدولى لنمو الطفل. وهو يعد من أهم مؤشرات سوء التغذية.

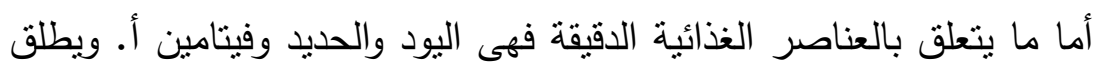
على الحرمان من هذه العناصر بـ "الجوع الخفى". والجدول التالى يوضح العلاقة بين الأشكال المختلفة للفقر وما يتبعه من سوء هوه تغذية وفرص تعليم الأطفال فى المستقبل(9).

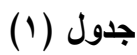

العلاقة بين الأثكال المختلفة لسوء التغذية وتعليم الأطفال

\begin{tabular}{|c|c|c|}
\hline التأثير على تعليم الأطفال & الأعراض المرضية & أثنكال سوء \\
\hline 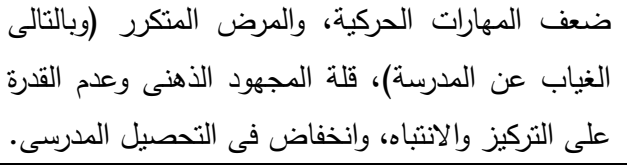 & التقزم و الهزال & نقص البروتين \\
\hline 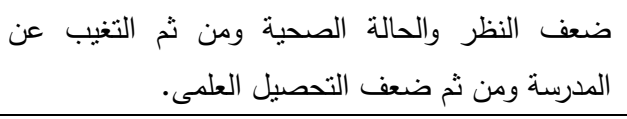 & ضعف الرؤية & نقص فيتامين أ \\
\hline 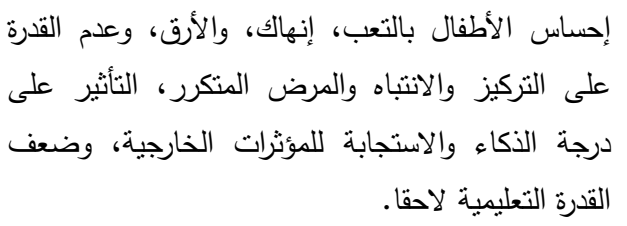 & أطفال حديثى الولادة & أنيمبا (نقص \\
\hline 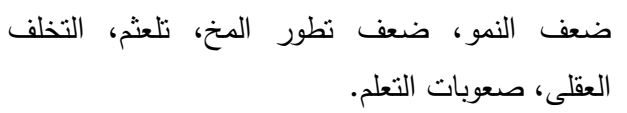 & 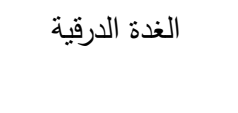 & نقص اليود \\
\hline
\end{tabular}

ويمكن الاستتاج من هذا الجدول أن تأثير الفقر وما يتبعه من سوء تغذية فى

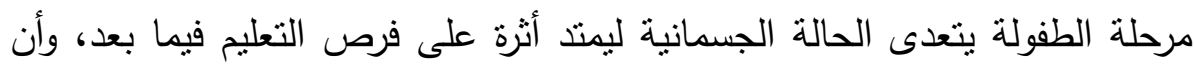

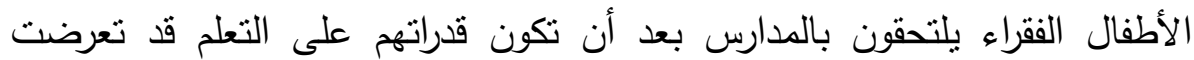
لأضرار من جراء سوء التغذية قد لا يمكن معالجتها. 
للتعرف على التفاوت فى مؤشرات الحالة التغذوية، وتتاول العناصر الغذائية الدقيقة بين الأطفال فى مصر وفقا للمستوى المعيشى، نم استخدام بيانات المسح السكانى موسرات الصحى لمصر A ...r. والجدير بالذكر أن قياس المستوى المعيثى فى هذا المسح

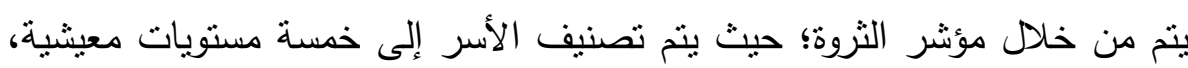
تتراوح بين الطبقة الفقيرة (أدنى مستوى) والطبقة الغنية (أعلى مستوى). ويعرض الجدول (r) الحالة التغذوية للأطفال حسب مستوى المعيشة بناء

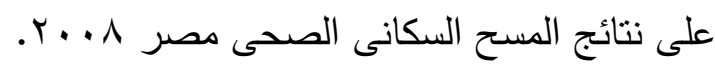

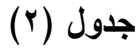

نسبة الأطفال دون الخامسة من العمر والذين تم تصنيفه

كناقصى تغذية حسب مؤشر الثروة

\begin{tabular}{|c|c|c|c|}
\hline الوزن بالنسبة للعمر & اللوزن بالنسبة & للعمر التقزم & مؤشر الثروة \\
\hline$v, 0$ & $r, \Lambda$ & $r$. & الطبقة الفقيرة \\
\hline $0, \varepsilon$ & $\uparrow, \Lambda$ & TV & الطبقة الغنية \\
\hline
\end{tabular}

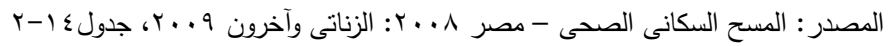

ويتضح من الجدول التفاوت فى مؤشرات سوء التغذية للطفل حسب المستوى المعيشى؛ حيث إن • ب\% من الأطفال الذين ينتمون إلى الطبقة الفقيرة يعانون من التقزم مقارنة بـ Y \% من الأطفال الذين بنتمون إلى الطبقة الغنية. وفيما يتعلق

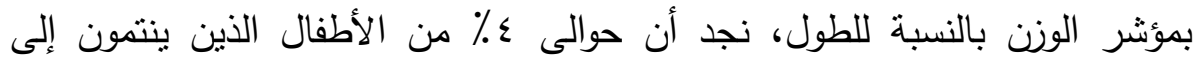
الطبقة الفقيرة مصابون بالهزال مقارنة بـ ب٪ من الأطفال الذين ينتمون إلى الطبقة

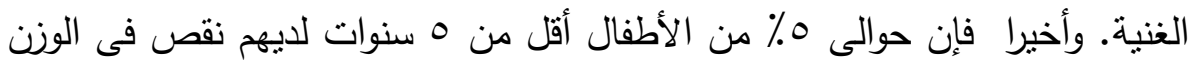
مقارنة بعمرهم، ويزداد نقص الوزن بالنسبة للعمر مع تدنى مسنوى المعيشى للأسرة. 
أى أن نسبة الأطفال التى تعانى من سوء التغذية، وما يؤدى إليه من عدم الحصول

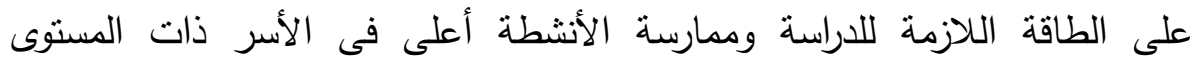

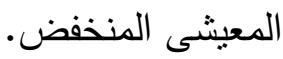

كما يعانى الطفل الفقير فى مصر من نقص التغذية فى المغذيات الدقيقة،

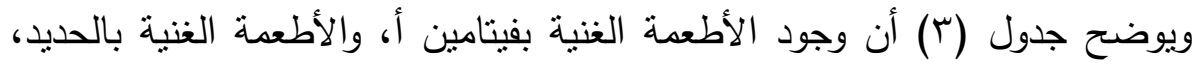

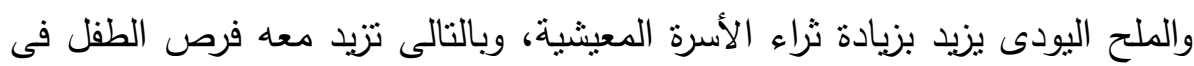
تناول كميات كافية من المغذيات الدقيقة.

جدول (ז) (ז)

تناول الغناصر الغذائية بين الأطفال الصغار حسب مؤثر الثروة

\begin{tabular}{|c|c|c|c|}
\hline 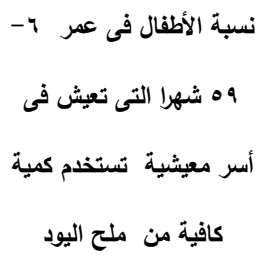 & 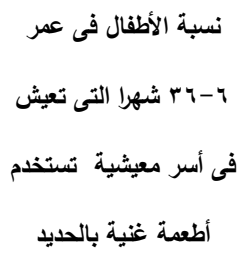 & 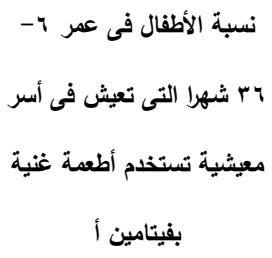 & مؤثر الثروة \\
\hline 07 & $7 \leq$ & ו & الطبقة الفقيرة \\
\hline 9. & $\vee q$ & $\varepsilon$. & الطبقة الغنية \\
\hline
\end{tabular}

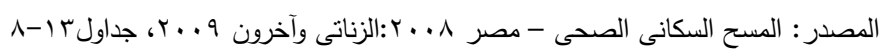

\section{ثانيا: العوائق التى تواجه الأطفال الفقراء فى التعليم}

فى هذا القسم من الدراسة سوف ينم عرض العوائق التى نواجه الأطفال الفقراء فى التى التعليم؛ حيث تتعدد هذه العوائق ومنها ما يتعلق بتأثنير الفقر النمائى على الأطفال

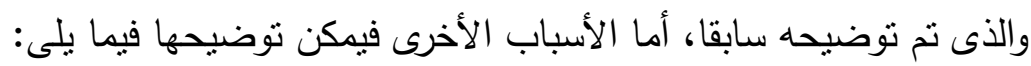




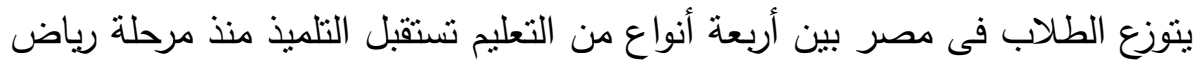

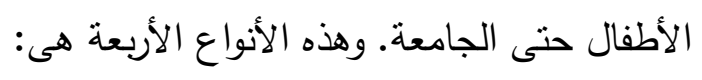

التعليم الحكومى: أو التعليم الرسمى وينقسم إلى تعليم حكومى عام وتعليم حكومى الأنى

$$
\text { بمصروفات (تجريبى). }
$$

التعليم الأزهرى: وهو تعليم مستقل تماما عن التعليم الحكومى وله مناهجه وإدارته وتمويله الخاص.

التعليم الخاص: يتتوع التعليم الخاص فى مصر ما بيلن تعليم خاص ينم باللغة

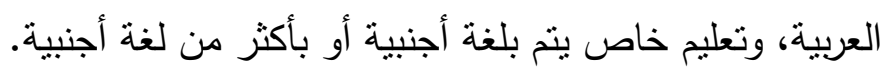

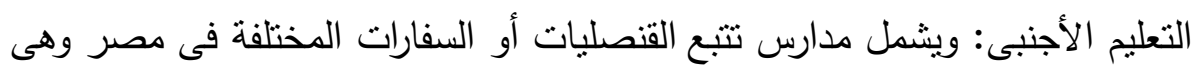

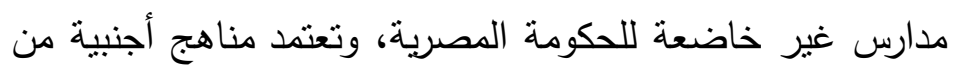
البلد الذى تحمل اسمه وتصريحه.

هذا التتوع فى التعليم - حتى داخل التعليم الحكومى بين حكومى عام

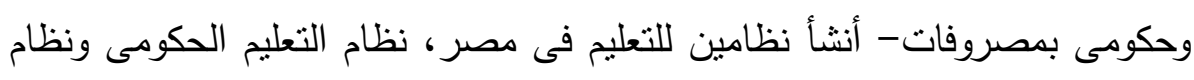

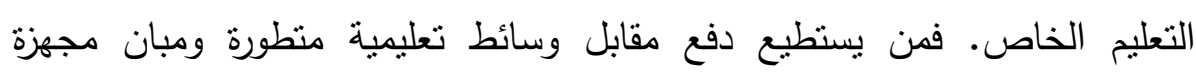

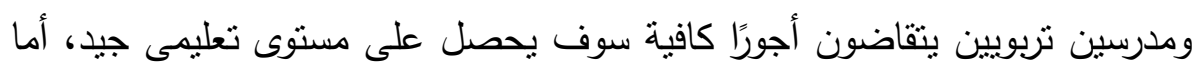

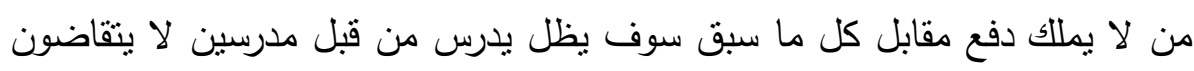

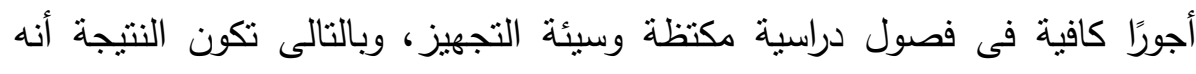

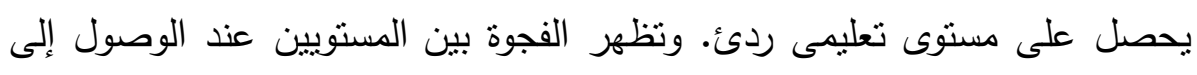

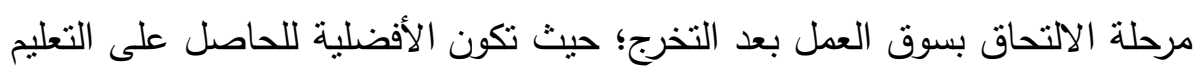

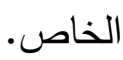

\section{التفاوت بين التعليم فى المدارس الرسمية والمدارس الخاصة}

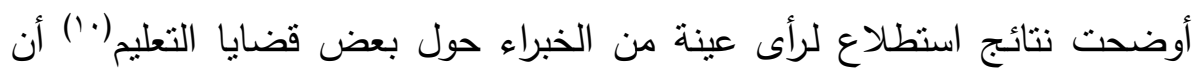

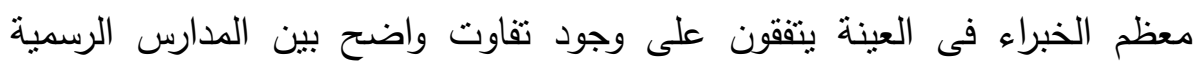

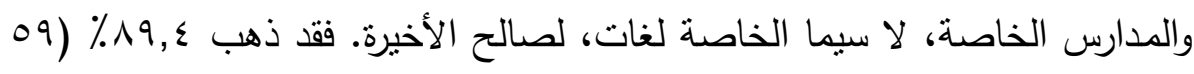


فردا) أن ثمة تفاوتا واضحا بين المدارس الرسمية والمدارس الخاصة لصالح الأخيرة.

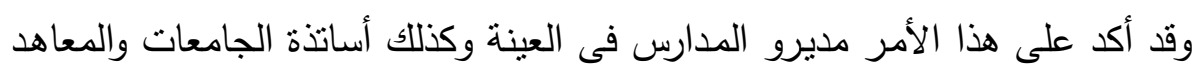

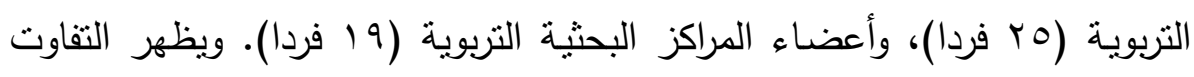

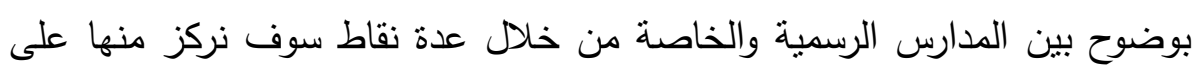

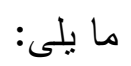

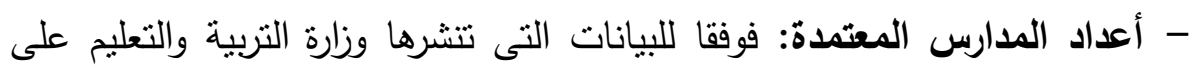

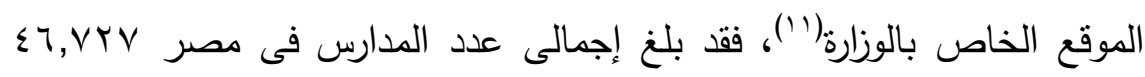

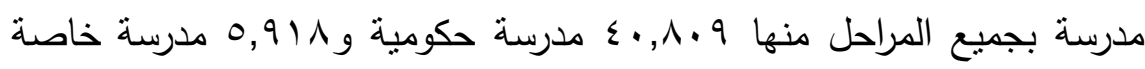

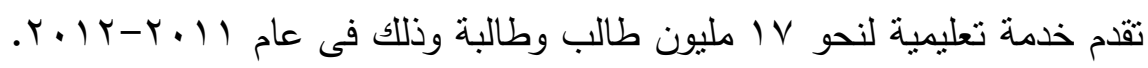

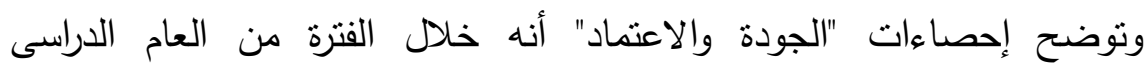

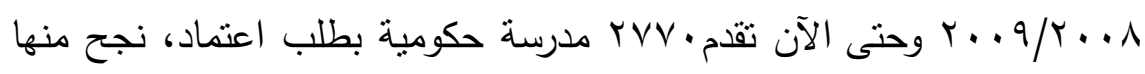

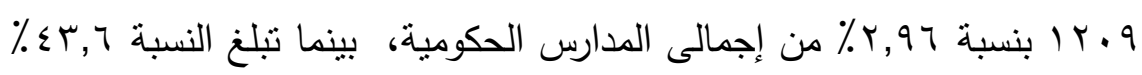

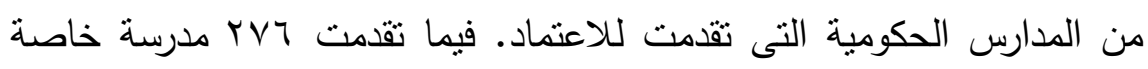

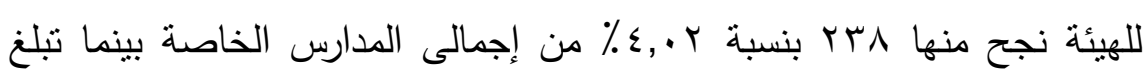
النسبة r, ؟1\% من المدارس الخاصة النى تقدمت للاعتماد.

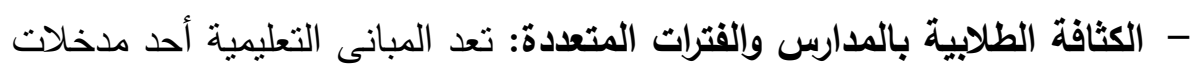

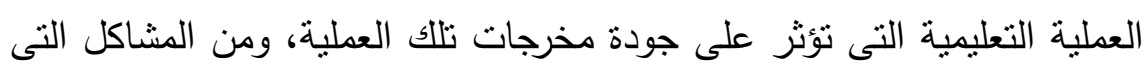

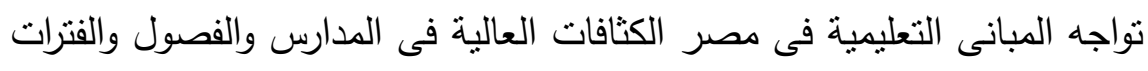

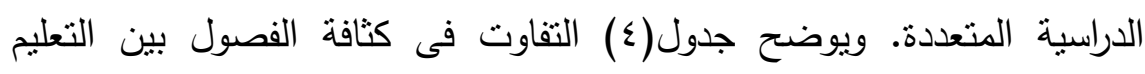
الحكومى، والخاص حسب المرحلة التعليمية. 


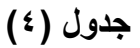

كثافة الفصول فى التعليم الحكومى والخاص حسب المرحلة التعليمية

\begin{tabular}{|c|c|c|}
\hline \multicolumn{2}{|c|}{$r+\mid r / r \cdot 11$} & \multirow{2}{*}{ المرحلة } \\
\hline خاص & حكومى & \\
\hline$r$. & r4 & ما قبل ابتدائى \\
\hline rr & $\varepsilon \varepsilon$ & الابتدائى \\
\hline$r$. & «1 & الإعدادى \\
\hline rq & $r q$ & الثانوى \\
\hline
\end{tabular}

المصدر: وزارة المالية والجهاز المركزى للتعبئة العامة

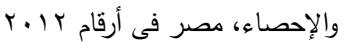

- تصل كثافة الفصل فى الـ 101 قرية الأثد فقرا فى مصر من •0-1 طالباً(r). ونظرا لعدم توافر عدد مناسب من المدارس فى القرى، فإن غالبية المدارس تعمل

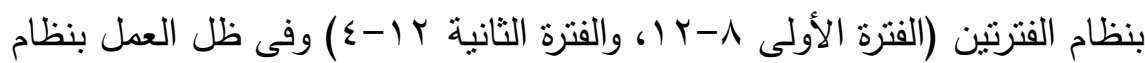
الفترتين فإن مدة الحصة تصل لنحو ثلاثين دقيقة وهى ليست كافية لتعليم

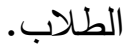

فيما يتعلق بالمبانى الدراسية التى تعمل بنظام تعدد الفترات نجد أن (ז'): ؟,؟ آلاف مبنى يعمل بذلك النظام على مستوى الجمهورية بنسبة V,7 1 .

\section{عدم الاستيعاب الكافى للأطفال فى هرحلة رياض الأطفال}

رغم الاتفاق على أهمية التعليم فى مرحلـة الطفولـة المبكرة، إلا أن فصول ريـاض

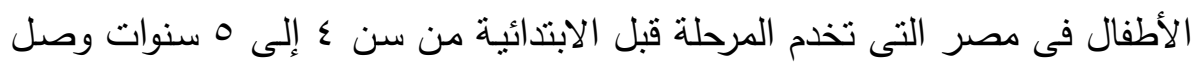

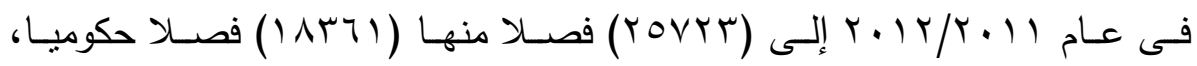

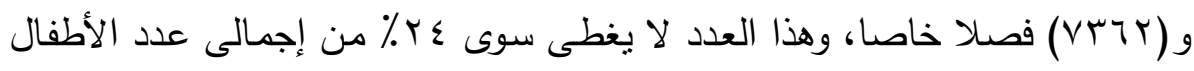
فى هذه المرحلة ـ وهى نسبة ضعيفة خاصـة أن مصر تستهدف الوصول إلى نسبة

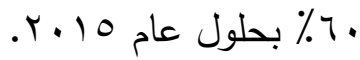




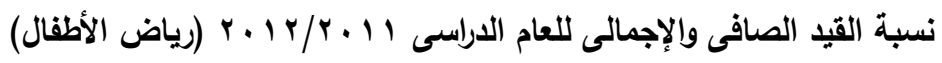

\begin{tabular}{|c|c|c|c|c|}
\hline الإجمالى القيا & الصافى القيد & السكان & تلاميذ السن & تلاميذ \\
\hline$r \varepsilon, r$ & Y $1, \varepsilon$ & r4.r17r & VVIYTA & $\Lambda V \leqslant V T$. \\
\hline
\end{tabular}

المصدر : وزارة المالية والجهاز المركزى للتعبئة العامة والاحصاء، مصر فى أرقام r ب ب r

\section{وجود هناطق همروهة هن التعليم الأساسى}

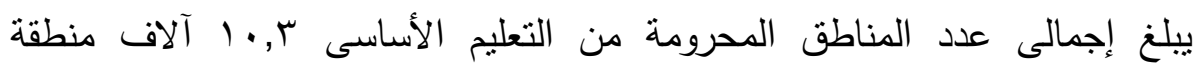

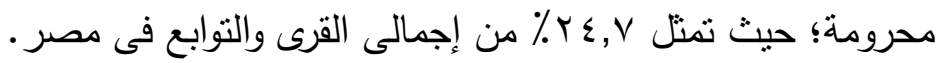

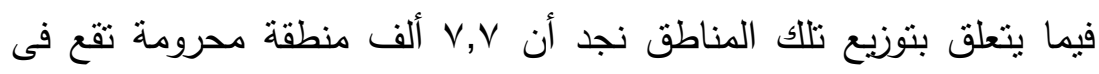

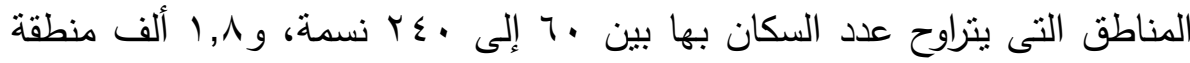

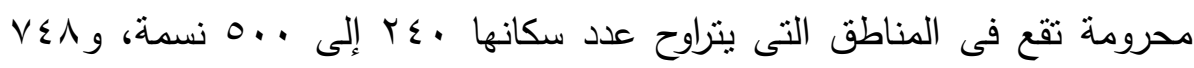
منطقة محرومة تقع فى المناطق التى يتعدى عدد سكانها . .0 نسمة. وقد نم تقدير

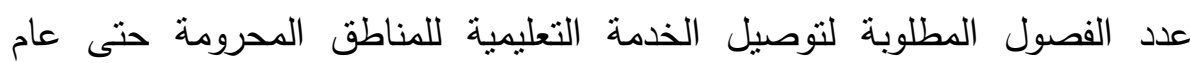

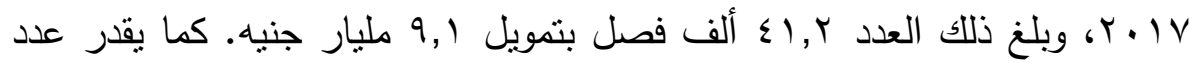

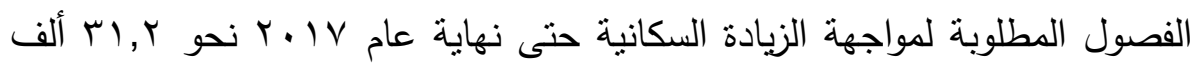
فصل بتكلفة إجمالية 9,9 مليارات جنيه( (1).

\section{التوزيع غير العادل للمعونات الدولية للتعليم الابتدائى}

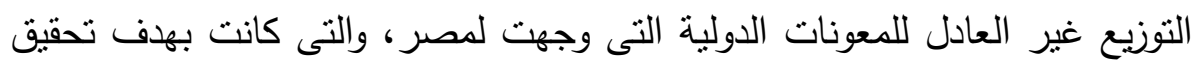

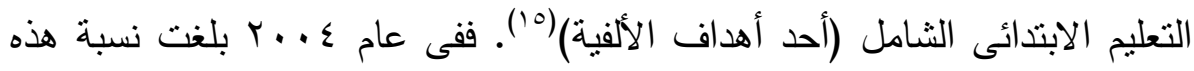

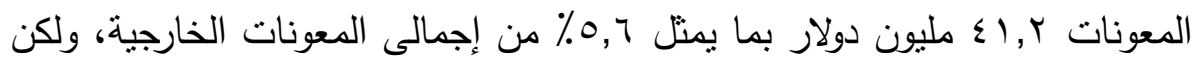

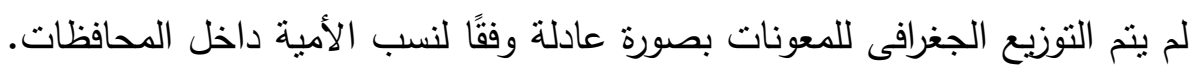

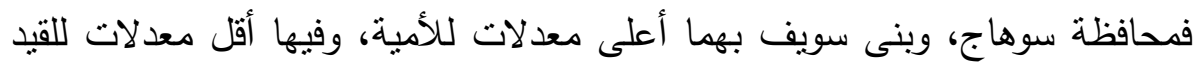

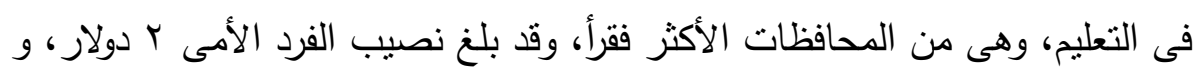


4, 1 دولار على التوالى. وفى الوقت نفسه، بلغ نصيب الفرد الأمى بمحافظة القاهرة

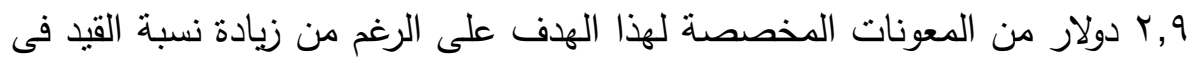

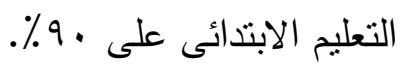

\section{تهيز الإنفاق العام على التعليم لصالح التعليم الجاهعى}

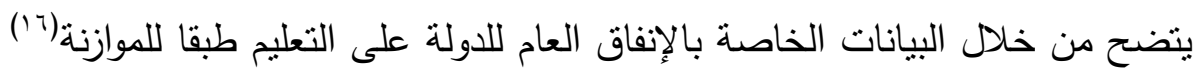

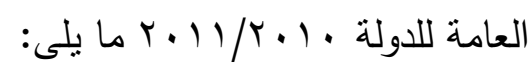

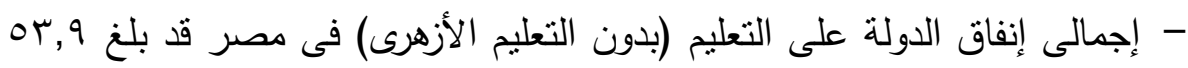
مليار جنيه. - r, • • مليار نصيب التعليم قبل الجامعى من إجمالى الإنفاق العام على التعليم،

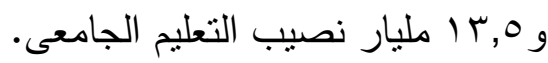

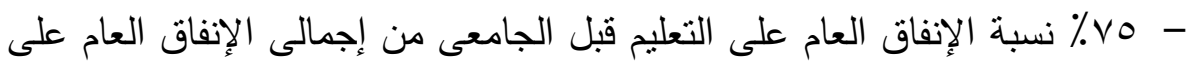
التعليم - - مب نسبة الإنفاق العام على التعليم الجامعى من إجمالى الإنفاق العام على

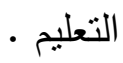
- نصيب التعليم قبل الجامعى من جملة الطلبة المقيدين فى التعليم عام

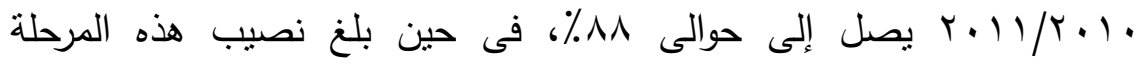

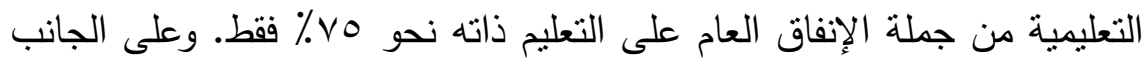

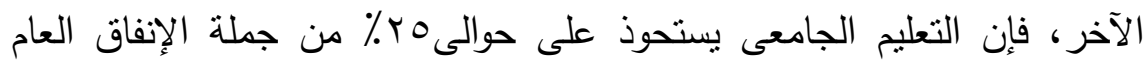

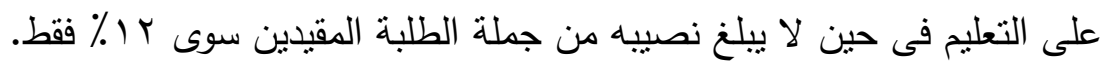

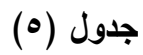

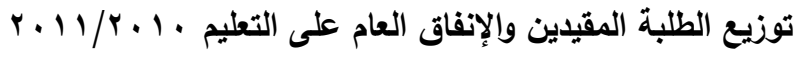




\begin{tabular}{|c|c|c|c|}
\hline & التعليم الجامعى & الجامعى التعليم قبل & \\
\hline & T. $\leqslant V I$ & 18.971 & عدد الطلاب (بالمليون) \\
\hline & $1 r, 0$ & $\varepsilon \cdot, r$ & الإنفاق العام (بالمليون) \\
\hline الدصدر : & $\left|r_{.}\right|$ & NV. 9 & \% من جملة الطلاب \\
\hline المالية و والجهاز & ro & vo & \% من جملة الإنفاق العام \\
\hline
\end{tabular}

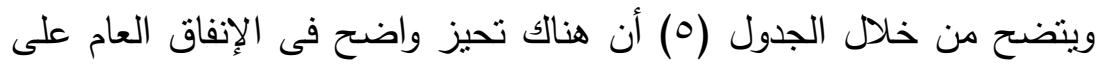
التعليم فى مصر لصالح التعليم الجامعى، وهو التعليم الذى لا يستقيد منه الفقراء استفادة كبيرة على عكس التعليم الأساسى؛ حيث إنه من المعروف أن احتمال

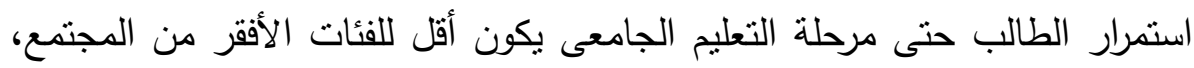

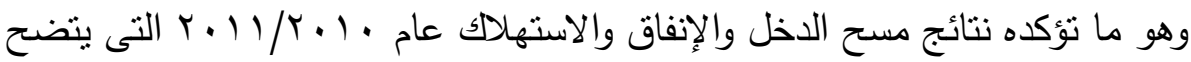
منها أن: - الغالبية العظمى من الفقراء لم تحصل سوى على تعليم ابتدائى على الأكثر.

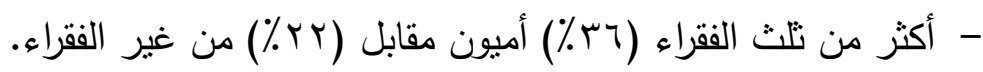

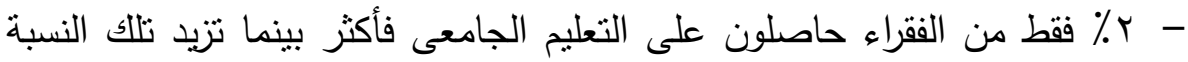

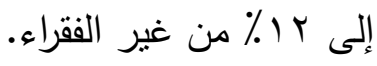

يشكل تدبير الأموال اللازمة للاروس الخصوصية ومجموعات التقوية والكتب الخارجية- والتى زاد الاعتماد عليهما نتيجة الخلل الذى تعانى منه العملية التعليميةعقبة كبيرة على الأسر الفقيرة التى بالكاد تسنطيع تدبير مصاريف المدرسة. ونتيجة لارتفاع نفقات التعليم وزيادة أعباء الأسر الفقيرة مع ارتفاع تكلفة المعيشة، يصبح 
على الأبناء بدورهم أن يشاركوا فى تحمل أعباء الأسرة؛ ويكون أول إجراء تتخذه

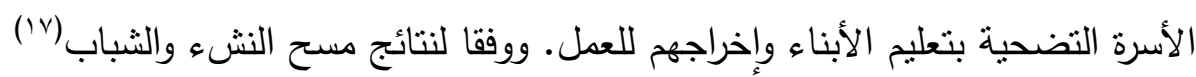

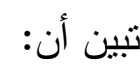
- يرتبط بقاء الطلاب فى التعليم بحسب مؤشر الثروة، فنجد أن الفارق بين

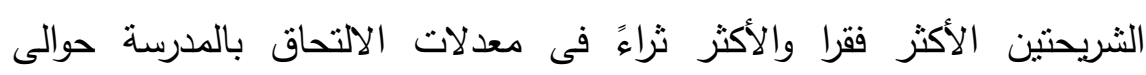

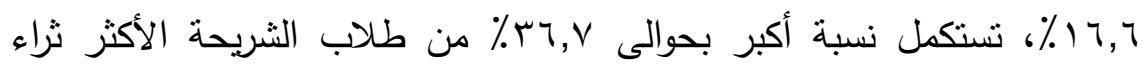

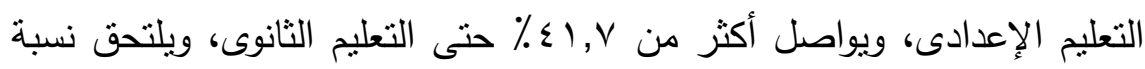

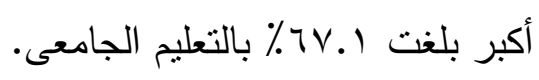

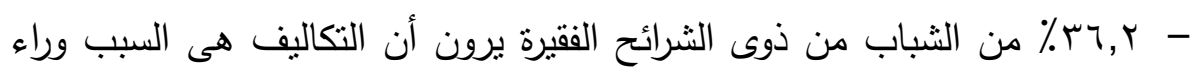

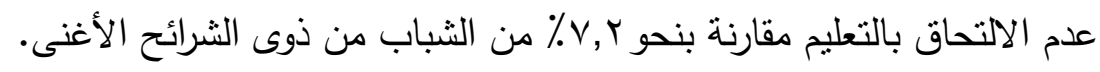

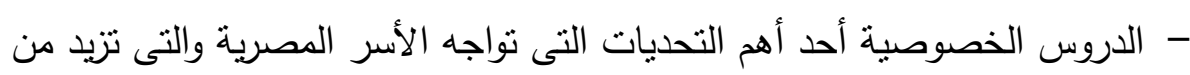
تكلفة التعليم بطريقة غير مباشرة. كما أوضح استطلاع رأى حول إنفاق أولياء الأمور على المستويات المختلفة

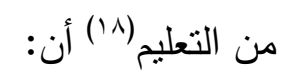

- نحو \% \% من الطلاب بالعينة يحصلون على دروس خصوصية فقط، كما أن

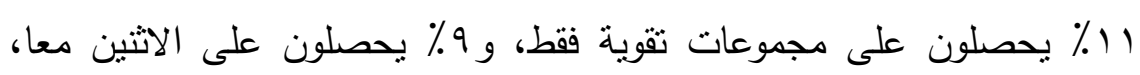

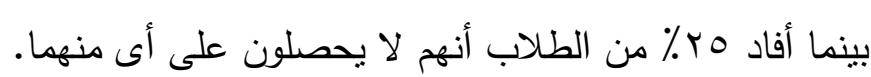
\% • - -

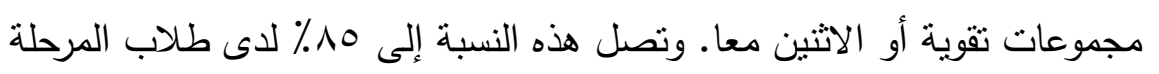

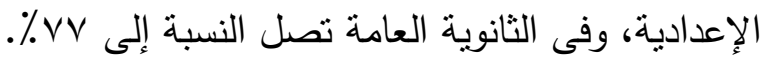

جدول (†) 


$$
\text { نسبة الطلاب الحاصلين على دروس خصوصية }
$$

\begin{tabular}{|c|c|}
\hline النسبة(\%) & المراحل \\
\hline v. & الابتدائية \\
\hline 10 & الإعدادية \\
\hline$V V$ & الثانوية \\
\hline
\end{tabular}

المصدر: استطلاع رأى حول إنفاق أولياء الأمور

$$
\text { على المستويات المختلفة من التعليم }
$$

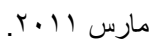

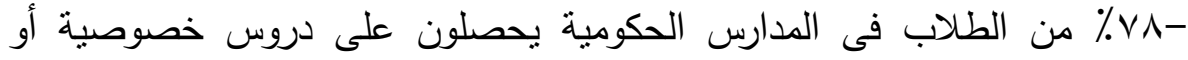
مجموعات تقوية أو الاثثين معا، وتصل هذه النسبة إلى آ٪ فى المدرس الخاصة.

\section{جدول (v)}

\begin{tabular}{|c|c|}
\hline النسبة(٪) & المراحل \\
\hline VA & حكومى \\
\hline 71 & خاص \\
\hline
\end{tabular}

نسبة الطلاب الحاصلين على دروس خصوصية

أو مجموعات تقوية أو الاثنين معا وفقا لنوع المدرسة لونة

المصدر: استطلاع رأى حول إنفاق أولياء الأمور

على المستويات المختلفة مـن التعليـم

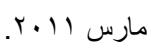

ارتباط البطالة بالتعليم

بطالة الثباب هى السمة الغالبة على شكل البطالة فى مصر، فوفقا لإحصائيات

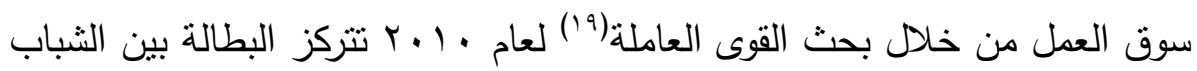




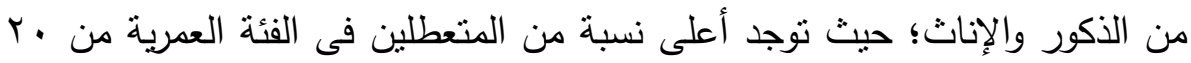

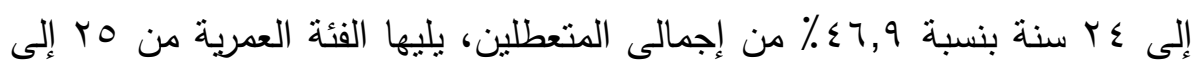

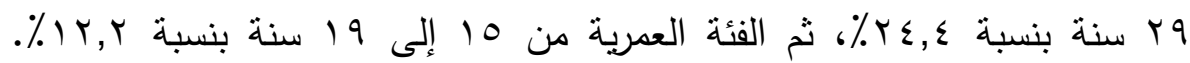
يضاف إلى ذلك أن البطالة فى مصر بطالة متعلمة فأعلى نسبة من البطالة بين

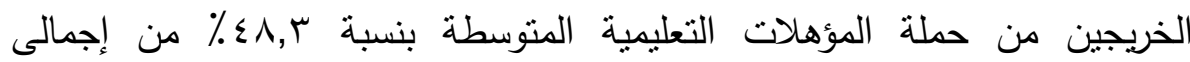

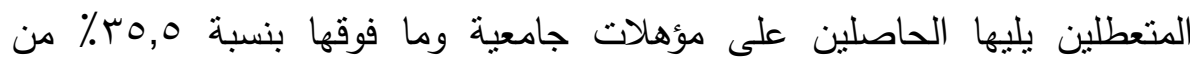

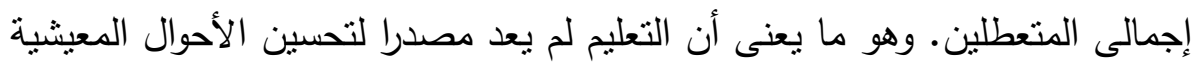

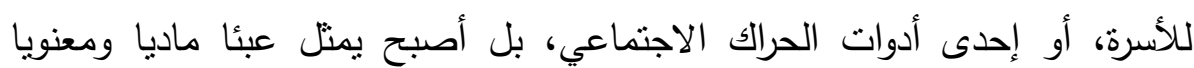

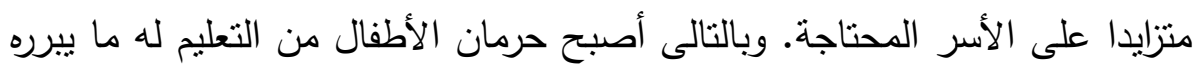

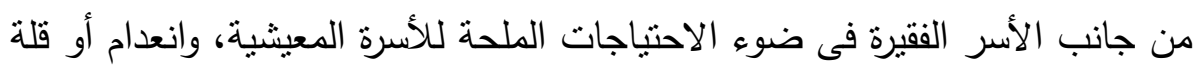
فرص الحصول على العمل لذوى التعليم المنوسط والمهنى.

\section{الانغفاض السنوى فى أعداد المببولين فى الجامعات الحكوهية}

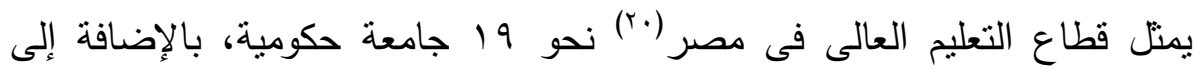
جامعة الأزهر ، و 0؛ كلية تكنولوجية، و آ معهر منوسط.

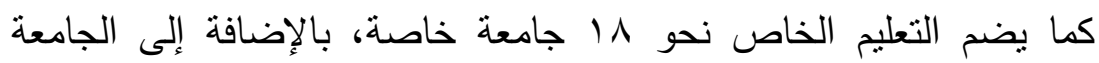

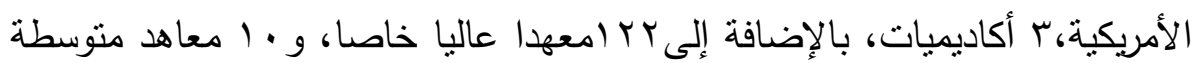

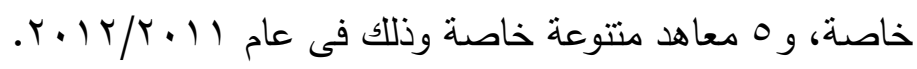

جدول (^)

تطور أعداد المقيدين وفقا لمؤسسات التطيم العالى خلال الفترة $(r \cdot 1 r / r+11-r+. V / r+. \tau)$

\begin{tabular}{|c|c|c|c|c|c|c|}
\hline $\begin{array}{l}r+11 \\
r+1 r\end{array}$ & $\frac{r+1 .}{r+1 \mid}$ & $\begin{array}{l}r \ldots q \\
r \ldots i .\end{array}$ & $\begin{array}{l}\mid r \ldots A \\
r \ldots q\end{array}$ & $\begin{array}{r}r \ldots v \\
r \ldots 1\end{array}$ & $\begin{array}{r}r \ldots r \\
r \ldots r\end{array}$ & مؤسسات التعليم العالى \\
\hline $1 . V V$ & $11 \%$. & $1 \varepsilon . r$ & $1 \leqslant \pi$ & $1 \leqslant 00$ & $1 \leqslant 17$ & الجامعات الحكومية \\
\hline$v_{4}$ & Tr & $T \varepsilon$ & 01 & $r$ r. & $r \varepsilon$ & الجامعات الخاصة \\
\hline
\end{tabular}

المصدر: الإحصاء السنوى للتعليم العالى، مركز المعلومات والتوثيق، وزارة التعليم العالى.

N 
يوضح جدول (^) الانخفاض السنوى فى أعداد الدقبولين فى الجامعات

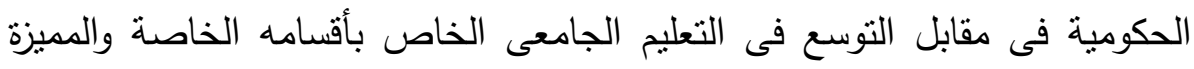
داخل الجامعات وفى كل كلية؛ حيث نكون المصاريف عادة مرتفعة بحيث تتاسب في الفي الطلاب القادرين فقط. ومن ثم، فأبناء الفقراء رغم دخولهم الجامعات الحكومية لن

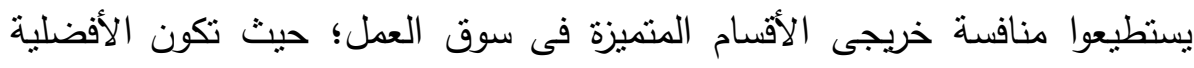

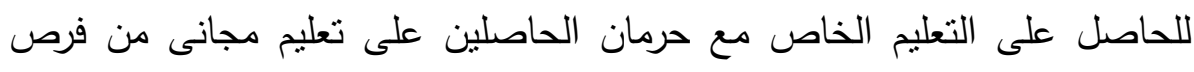
العمل التى هى الهذف الأساسى من التعليم والتدرج عبر مراحله المختلفة.

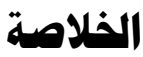
طرحت الدراسة هذا التساؤل: هل نضع "التعليم أولاً" أم "الفقر أولاً" فى سلم أولويات

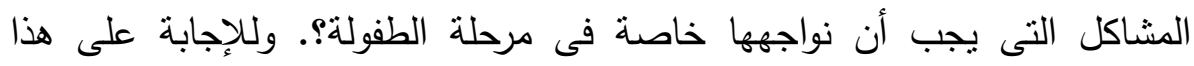

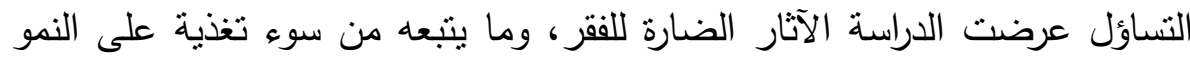

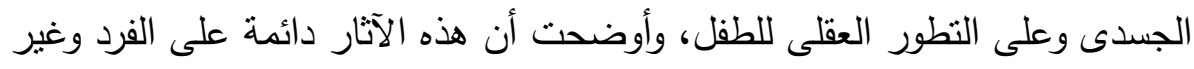

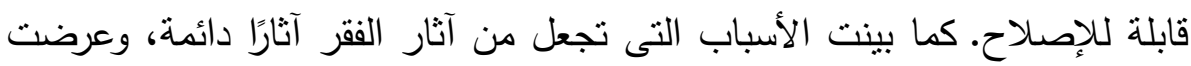
هذه الآثار.

عرضت الدراسة أيضا أسباب ضعف فرص الأطفال الفقراء فى التعليم. من هذه الأسباب ما يتعلق بالأطفال أنفسهم ، حيث إن ملايين الأطفال الفقراء يلتحقون

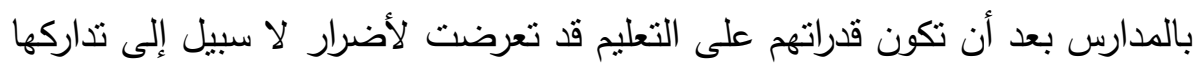

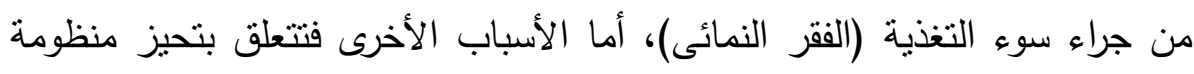

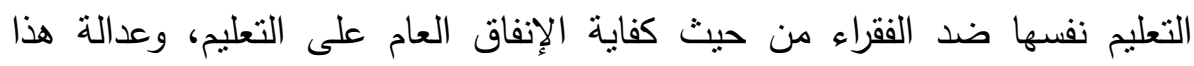

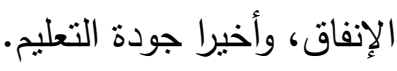

فى النهاية، إذا كان يتعين اختيار بديل واحد التعليم أم الفقر، فالإجابة كما براها الباحث هى الفقر وذللك لأنه مع الفقر لا يوجد لدى الطفل فرصة بعكس التعليم لإيل

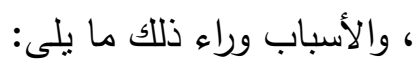


- فرص الطفل فى النمو لها مدى زمنى محدد، بعدها لا يوجد لدى الطفل فرصة

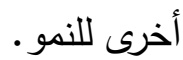

- النمو البيولوجى والعقلى للطفل لا يمكن أن ينتظر حتى تتخلص أسرته المعيشية من الفقر.

- الفقر فى مرحلة الطفولة المبكرة وبالتالى سوء التخذية يسبب ضررا مدى الحياة لعقول وأجسام الأطفال غير قابلة للتصويب حتى لو نم إمدادهم بالغذاء المناسب

\section{المراجع}

-online at www.unesco.org/new/ar/education/education-first/

r- ليلى كرم الدين، أهم التجارب والنماذج الدولية الناجحة فى مجال رعاية وتربية الأطفال

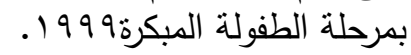

-online at www.gulfkids.com/ar/book21-1110.htm.

$$
\text { ع- مركز أنباء الأمم المتحدة - "بان كى مون يؤكد أهمية التغذية فى سن مبكرة" }
$$

-online at www.un.org/arabic/news/story.asp?NewsID

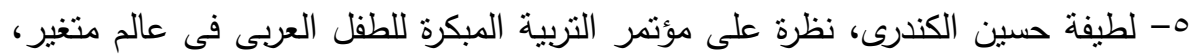

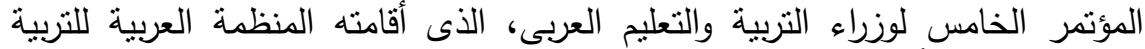

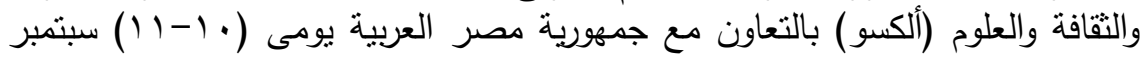

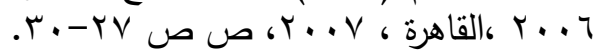

-http://www.emoe.org/Ministry/inside.aspx?sub1=arabmoe5\&sub2=papers

$$
\text { ؟- ليلى كرم الدين، مرجع سابق، } 999 \text { (،صع ـ. }
$$

-Reader. FAO, 2005, Nutrition Education in Primary Schools, Vol. 1: The $\quad-V$ Preparatory Unit 2, Malnutrition and its Causes.

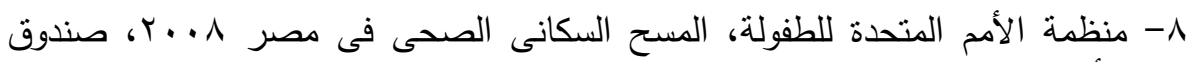

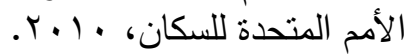


-FAO, Nutrtion Education in Primary Schools, Vol. 1: The Reader Preparatory - -9 Unit 2, Malnutrition and its Causes, , 2005.

• ا-ناهد رمزى وآخرون، العدالة الاجتماعية فى التعليم الأساسى (المجلد الأول)، القاهرة،

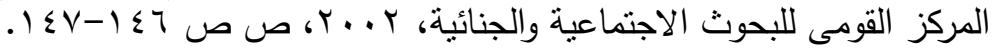

-www.naqaae.eg/services/naqaae-acc-inst.htm1 .

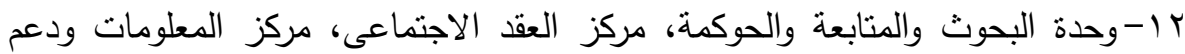

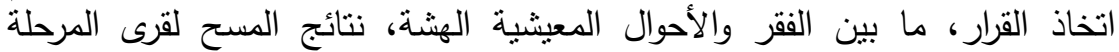

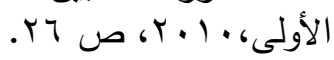

با - مركز المعلومات ودعم اتخاذ القرار، واقع التعليم فى مصر ... حقائق وآراء،

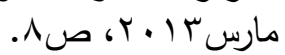

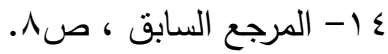

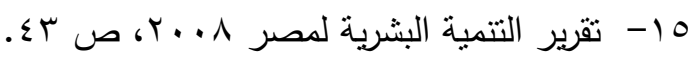

- Online at: http:services.moe.gov.eg/books/011012/4teacherStaff.pdf $\quad-17$

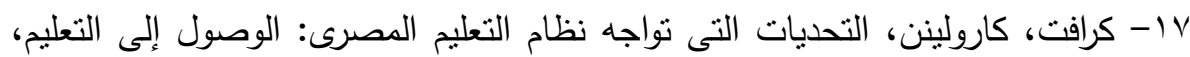

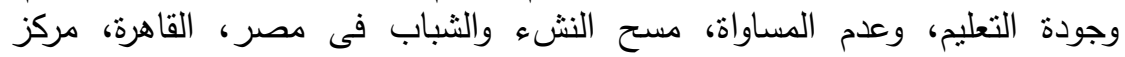

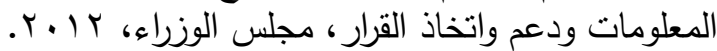

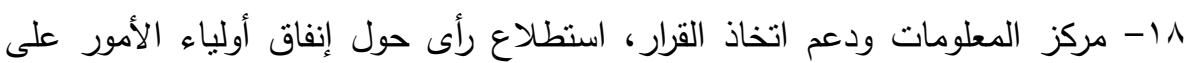

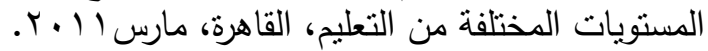

9 19- الجهاز المركزى للتعبئة العامة والإحصاء: ملخص نتائج بحث القوى العاملة لعام .$r \cdot 1$. • r- الإحصاء السنوى للتعليم العالى، مركز المعلومات والتوثيق، وزارة التعليم العالى. 


\title{
Abstract
}

\section{EDUCATION FIRST OR POVERTY FIRST}

\begin{abstract}
Abeer Saleh
The study tries to answer the following question: can education win its batlle with poverty if we start with it?. We try answer through reviewing the danger of developmental poverty on children and the chances of their education hereafter we also review the obstacles that face poor children in education. The paper chose childhood which extends, according to the definition of The United Nations, from birth till 18 years old.
\end{abstract}


